\title{
2-(6-Hydroxyhexylthio)-5,8-dimethoxy-1,4-naphthoquinone Induces Apoptosis through ROS-Mediated MAPK, STAT3, and NF- $\kappa$ B Signalling Pathways in Lung Cancer A549 Cells
}

\author{
Gui-Nan Shen, ${ }^{1}$ Cheng Wang, ${ }^{2}$ Ying-Hua Luo, ${ }^{3}$ Jia-Ru Wang, ${ }^{1}$ Rui Wang, ${ }^{1}$ Wan-Ting Xu, \\ Yi Zhang, ${ }^{1}$ Yu Zhang, ${ }^{1}$ Dong-Jie Zhang $(1),{ }^{4,5}$ and Cheng-Hao Jin $\mathbb{C}^{1,4,5}$ \\ ${ }^{1}$ Department of Biochemistry and Molecular Biology, College of Life Science \& Technology, \\ Heilongjiang Bayi Agricultural University, Daqing, Heilongjiang 163319, China \\ ${ }^{2}$ Pharmacy Department, Daqing Oilfield General Hospital, Daqing 163001, China \\ ${ }^{3}$ Department of Grass Science, College of Animal Science \& Veterinary Medicine, Heilongjiang Bayi Agricultural University, \\ Daqing, Heilongjiang 163319, China \\ ${ }^{4}$ Department of Food Science and Engineering, College of Food Science \& Technology, Heilongjiang Bayi Agricultural University, \\ Daqing, Heilongjiang 163319, China \\ ${ }^{5}$ National Coarse Cereals Engineering Research Center, Daqing, Heilongjiang 163319, China
}

Correspondence should be addressed to Dong-Jie Zhang; byndzdj@126.com and Cheng-Hao Jin; jinchenghao3727@qq.com

Received 3 November 2019; Revised 8 June 2020; Accepted 8 July 2020; Published 12 August 2020

Academic Editor: Nativ Dudai

Copyright (c) 2020 Gui-Nan Shen et al. This is an open access article distributed under the Creative Commons Attribution License, which permits unrestricted use, distribution, and reproduction in any medium, provided the original work is properly cited.

Two novel compounds, 2-(2-hydroxyethylthio)-5,8-dimethoxy-1,4-naphthoquinone (HEDMNQ) and 2-(6-hydroxyhexylthio)5,8-dimethoxy-1,4-naphthoquinone (HHDMNQ), were synthesized to investigate the kill effects and mechanism of 1,4naphthoquinone derivatives in lung cancer cells. The results of the CCK-8 assay showed that HEDMNQ and HHDMNQ had significant cytotoxic effects on A549, NCI-H23, and NCI-H460 NSCLC cells. Flow cytometry and western blot results indicated that HHDMNQ induced A549 cell cycle arrest at the G2/M phase by decreasing the expression levels of cyclin-dependent kinase 1/ 2 and cyclin B1. Fluorescence microscopy and flow cytometry results indicated that HHDMNQ could induce A549 cell apoptosis, and western blot analysis showed that HHDMNQ induced apoptosis through regulating the mitochondria pathway, as well as the MAPK, STAT3, and NF- $\kappa$ B signalling pathways. Flow cytometry results showed that intracellular reactive oxygen species (ROS) levels were increased after HHDMNQ treatment, and western blot showed that ROS could modulate the intrinsic pathway and MAPK, STAT3, and NF- $\kappa$ B signalling pathways. These effects were blocked by the ROS inhibitor N-acetyl-L-cysteine in A549 cells. Our findings suggest that compared with HEDMNQ, HHDMNQ had the stronger ability to inhibit the cell viability of lung cancer cells and induce apoptosis by regulating the ROS-mediated intrinsic pathway and MAPK/STAT3/NF- $\kappa \mathrm{B}$ signalling pathways. Thus, HHDMNQ might be a potential antitumour compound for treating lung cancer.

\section{Introduction}

Lung cancer mainly occurs in the bronchial epithelium, and it causes the most cancer-related deaths worldwide [1]. Nonsmall-cell lung cancer (NSCLC) is a highly metastatic and aggressive lung cancer subtype, accounting for about $80 \%$ of lung cancer cases [2]. Standard therapies include surgery, chemotherapy, and molecular-targeted therapy, but the mortality rate for lung cancer patients is still high [3-5].
Therefore, it is highly desirable to find more effective novel therapeutic targets and develop drugs with high efficacy and low toxicity for NSCLC patients.

Mitogen-activated protein kinases (MAPKs), such as extracellular signal-regulated kinase (ERK), c-Jun $\mathrm{N}$ terminal kinase (JNK), and p38, are involved in cancer cell proliferation, migration, and apoptosis [6-8]. The nuclear factor $-\kappa \mathrm{B}(\mathrm{NF}-\kappa \mathrm{B})$ signalling pathway includes NF- $\kappa \mathrm{B}$ and nuclear factor of kappa light polypeptide gene enhancer in 
B-cells inhibitor, alpha $(\mathrm{I} \kappa \mathrm{B}-\alpha)$, and has a crucial role in the regulation of cell survival and apoptosis [9]. Signal transducer and activator of transcription 3 (STAT3) is involved in the activation of immunity and apoptosis, and its activation depends on cytokines and growth factors [10]. In addition, some studies have demonstrated that the phosphorylation of MAPKs is associated with activation of the NF- $\kappa$ B signalling pathway [11]. Furthermore, NF- $\kappa$ B and STAT3 are constitutively activated in lung cancer and are promising targets for the development of novel cancer drugs [12-14]. Thus, the MAPK, STAT3, and NF- $\kappa$ B signalling pathways may be key targets for cancer therapy.

Reactive oxygen species (ROS) are produced by mitochondrial oxidative phosphorylation and play crucial roles as intracellular messengers in cell proliferation, differentiation, and survival [15]. Oxidative stress can induce excessive production of ROS, leading to cellular damage and apoptosis [16]. Furthermore, ROS play essential roles in maintaining various biological functions by modulating many signal transduction pathways [17]. Therefore, controlling the levels of ROS is important for the treatment of cancer.

The 1,4-naphthoquinone derivatives have been exploited in drug development because of their high anticancer activity and low cytotoxicity [18]. Thus, the anticancer effects of the 1,4-naphthoquinone compound have been the focus of recent studies [18-20]. The pharmacophore of 1,4naphthoquinone imparts anticancer activity in a number of drugs, such as menadione, shikonin, and doxorubicin. The 1,4-naphthoquinone derivatives have been synthesized from natural terpenoids and p-benzoquinones, followed by side chain transformation. Several studies have shown that 1,4naphthoquinone derivatives with substituent groups at the C-2 site can promote antiproliferative activity [21-23].

In this study, we synthesized two novel naphthoquinone derivatives, 2-(2-hydroxyethylthio)-5,8-dimethoxy-1,4-naphthoquinone (HEDMNQ) and 2-(6-hydrox yhexylthio)-5,8-dimethoxy-1,4-naphthoquinone (HHD MNQ). Then, we investigated the effects of HEDMNQ and HHDMNQ on cell viability, cell cycle, cell apoptosis, apoptosis-related signalling pathways, and intracellular ROS levels in A549 lung cancer cells.

\section{Materials and Methods}

2.1. Synthesis of HEDMNQ and HHDMNQ. Aluminum chloride $(1.06 \mathrm{M})$ and sodium chloride $(0.484 \mathrm{M})$ were heated to $150^{\circ} \mathrm{C}$, followed by the addition of 1,4-dimethoxybenzene $(0.12 \mathrm{M})$ and maleic anhydride $(0.24 \mathrm{M})$. The mixture was incubated at $170-180^{\circ} \mathrm{C}$ for $5-10 \mathrm{~min}$. After cooling, $1800 \mathrm{~mL}$ of double distilled water (DDW) and $120 \mathrm{~mL}$ of $98 \%$ hydrogen chloride were added to the mixture, with constant stirring for 12-18 h. Then, naphthazarin was obtained by recrystallizing the filter residue. Naphthazarin $(100 \mathrm{mM})$, butyraldehyde $(200 \mathrm{~mL})$, sodium hydrosulfite $(60 \mathrm{mM})$, DDW $(200 \mathrm{~mL})$, and tetrabutylammonium bromide $(2 \mathrm{~g})$ were stirred for $2 \mathrm{~h}$ at room temperature, and a mixture of sodium dithionite $(10.6 \mathrm{~g})$, $50 \%$ sodium hydroxide solution $(40 \mathrm{~mL})$, and dimethyl sulfate $(25 \mathrm{~mL})$ was added every $3 \mathrm{~h}$. After constant stirring for 12-18 h, 1,4,5,8-tetramethoxynaphthalene was generated and dissolved in acetonitrile $(450 \mathrm{~mL})$ and chloroform $(150 \mathrm{~mL})$. Ceric ammonium nitrate $(54 \mathrm{~g})$ was added to the solution and stirred for $0.5-1 \mathrm{~h}$, and 5,8-dimethoxy-1,4naphthoquinone was obtained by recrystallizing. Next, 2hydroxy-1-ethanethiol $(1.5 \mathrm{mM})$ and 6-mercapto-1-hexanol $(1.5 \mathrm{mM})$ were added to a solution of 5,8-dimethoxy-1,4naphthoquinone $(1 \mathrm{mM})$ in $\mathrm{MeOH}(30 \mathrm{~mL})$. The mixture was stirred for $4 \mathrm{~h}$ at room temperature and stirred for $5 \mathrm{~min}$ with sodium dichromate $(0.6 \mathrm{mM})$ and sulfuric acid $(0.6 \mathrm{mM})$. Two novel compounds, HEDMNQ and HHDMNQ, were separated by chromatography. Nuclear magnetic resonance (NMR) spectra were recorded on a JNM-AL $400(400 \mathrm{MHz})$ spectrometer. Chemical shifts (d) are given in ppm downfield from tetramethylsilane as the internal standard. Mass spectra were collected with the $\mathrm{AB}$ SCIEX API 2000 LC/MS/MS (Applied Biosystems, Inc., Foster City, CA, USA) and LCMS-IT-TOF (Shimadzu Scientific Inc., Beijing, China) systems.

2.2. Cell Culture. Human lung cancer cell lines A549, NCI$\mathrm{H} 23$, and NCI-H460 were obtained from the American Type Culture Collection (Manassas, VA, USA); and normal lung IMR-90, liver L-02, and stomach GES-1 cell lines were purchased from Saiqi Biological Engineering Co., Ltd. (Shanghai, China). The cells were cultured in Dulbecco's Modified Eagle's Medium (DMEM) supplemented with 10\% fetal bovine serum (FBS) and grown at $37^{\circ} \mathrm{C}$ in a humidified atmosphere with $5 \% \mathrm{CO}_{2}$.

2.3. Cell Counting Kit-8 Assay Determination of Cell Viabilities. Briefly, the human lung cancer A549, NCI-H23, and NCI-H460 cells and normal lung IMR-90, liver L-02, and stomach GES-1 cell lines were counted and seeded into 96-well culture plates followed by adherence for $24 \mathrm{~h}$. Then, the cells were treated with different concentrations of shikonin, fluorouracil (5-FU), HEDMNQ, and HHDMNQ (0, $1,3,10,30$, and $100 \mu \mathrm{M})$ for $24 \mathrm{~h}$. Followed by starvation for $2 \mathrm{~h}, 10 \mu \mathrm{L}$ of CCK-8 solution (Beyotime Biotechnology, Beijing, China) was added to each well. After incubation for $1 \mathrm{~h}$ at $37^{\circ} \mathrm{C}$, the absorbance of the solution was measured at $450 \mathrm{~nm}$ with an automatic microplate reader (BioTek Instruments, Inc., Winooski, VT).

In addition, the A549, NCI-H23, NCI-H460, IMR-90, L-02, and GES-1 cells were seeded in 96-well plates. According to the $\mathrm{IC}_{50}$ value of shikonin, 5-FU, HEDMNQ, and HHDMNQ in human lung cancer and normal cell lines, the cells were treated with HEDMNQ and HHDMNQ for 3, $6,12,24$, and $36 \mathrm{~h}$. Next, $10 \mu \mathrm{L}$ of CCK- 8 solution was added to the cells and measured by using an automatic microplate reader.

2.4. Flow Cytometry Determination of Cell Cycle. A549 cells were incubated with $6 \mu \mathrm{M}$ HHDMNQ for the indicated times $(3,6,12$, and $24 \mathrm{~h})$, and the cells were harvested and fixed in $70 \%$ ethanol at $4^{\circ} \mathrm{C}$ for $24 \mathrm{~h}$. Cell 
suspensions were resuspended in $195 \mu \mathrm{L}$ binding buffer and incubated with RNase and propidium iodide (PI) (Beyotime Biotechnology) for $30 \mathrm{~min}$ in the dark at $37^{\circ} \mathrm{C}$. Then, the cells were analyzed by flow cytometry (Beckman Coulter, Brea, CA, USA) with a $488 \mathrm{~nm}$ argon laser.

2.5. Fluorescence Microscopy Determination of Apoptosis. Briefly, $4 \times 10^{4}$ cells/well of A549 cells were cultured onto 6well plates followed by adherence overnight and subsequent treatment with $6 \mu \mathrm{M}$ HHDMNQ for the indicated times (3, $6,12$, and $24 \mathrm{~h})$. Then, the cells were harvested and suspended in phosphate-buffered saline (PBS), after which the cell suspensions were stained with Hoechst 33342 and PI (Beyotime Biotechnology) for $15 \mathrm{~min}$ in the dark and analyzed by fluorescence microscopy (EVOS FL, Life technology, USA).

2.6. Flow Cytometry Determination of Apoptosis. A549 cells were incubated with $6 \mu \mathrm{M}$ HHDMNQ for the indicated times $(3,6,12$, and $24 \mathrm{~h})$, and the cells were harvested and resuspended in PBS. Then, the cell suspensions were stained with Annexin V-FITC and PI (Beyotime Biotechnology) for $15 \mathrm{~min}$ in the dark and analyzed by flow cytometry (Beckman Coulter).

2.7. Flow Cytometry Determination of ROS. Many studies have shown that DCFH-DA staining is one of the most widely used techniques for directly measuring the redox state of cells. A549 cells were incubated with $6 \mu \mathrm{M}$ HHDMNQ for the indicated times (3, 6, 12, and $24 \mathrm{~h}$ ), and incubated with $10 \mu \mathrm{M} 2^{\prime}, 7^{\prime}$-dichlorofluorescein diacetate (DCFH-DA) (Merck, Shanghai, China) for $30 \mathrm{~min}$ at $37^{\circ} \mathrm{C}$. Then, the cells were centrifuged at $5,000 \times g$ for $5 \mathrm{~min}$, washed, and resuspended in PBS. $2^{\prime}, 7^{\prime}$-Dichlorofluorescein fluorescence was analyzed by flow cytometry.

2.8. Western Blot Analysis of Proteins. A549 cells were harvested and lysed in lysis buffer. The supernatant was collected after centrifugation at $12,000 \times g$ for $30 \mathrm{~min}$ at $4^{\circ} \mathrm{C}$ and dissolved at $30 \mu \mathrm{g}$ proteins per $20 \mu \mathrm{L}$ with DDW and $5 \times$ buffer. The proteins were separated on 10\% SDS-PAGE gels and electrotransferred onto nitrocellulose membranes. Then, the membranes were blocked in 5\% skim milk and incubated with primary antibodies overnight at $4^{\circ} \mathrm{C}$. After incubation with secondary antibodies, the protein bands were detected using enhanced chemiluminescence detection reagents. The intensity of the bands was determined using the ImageJ software.

2.9. Statistical Analysis. The results were analyzed by comparison between different groups. The $\mathrm{IC}_{50}$ was calculated by the GraphPad Prism 5.0 software. The continuous data were analyzed by one-way analysis of variance followed by Tukey's post-hoc tests using the SPSS 18.0 statistical software. Statistically significant values were defined as $p<0.05$. All of the experiments were replicated three times and presented as mean \pm standard deviation (SD).

\section{Results}

3.1. Synthesis of the 1,4-Naphthoquinone Derivatives HEDMNQ and HHDMNQ. To improve anticancer activity and reduce the side effects of 1,4-naphthoquinone, we synthesized HEDMNQ and HHDMNQ (Figure 1). By performing NMR at a wavelength of $400 \mathrm{MHz}$, we analyzed the $\mathrm{H}, \mathrm{C}$ and mass spectra in deuterated chloroform solvent and identified the following structures.

HEDMNQ : ${ }^{1} \mathrm{H}-\mathrm{NMR}\left(\mathrm{CDCl}_{3}, 400 \mathrm{MHz}\right): \delta 7.34(\mathrm{~d}$, $J=9.6 \mathrm{~Hz}, 1 \mathrm{H}), 7.28(\mathrm{~d}, J=9.6 \mathrm{~Hz}, 1 \mathrm{H}), 6.61(\mathrm{~s}, 1 \mathrm{H}), 3.96(\mathrm{~s}$, $6 \mathrm{H}), 3.93(\mathrm{t}, J=6.4 \mathrm{~Hz}, 2 \mathrm{H}), 3.05(\mathrm{t}, J=6.4 \mathrm{~Hz}, 2 \mathrm{H}) ;{ }^{13} \mathrm{C} \mathrm{NMR}$ $\left(\mathrm{CDCl}_{3}, 150 \mathrm{MHz}\right): \delta 181.8(\mathrm{C}-1), 181.6(\mathrm{C}-4), 154.3(\mathrm{C}-5)$, 153.6 (C-8), 153.5 (C-2), 127.8 (C-3), 123.3 (C-7), 121.0 (C6), $120.7(\mathrm{C}-10), 119.7(\mathrm{C}-9), 56.8\left(\mathrm{OCH}_{3}\right), 56.8\left(\mathrm{OCH}_{3}\right)$, $59.7\left(\mathrm{C}-1^{\prime}\right), 31.9\left(\mathrm{C}-2^{\prime}\right) ; m / z 316.9(M+\mathrm{Na})^{+}$.

HHDMNQ : ${ }^{1} \mathrm{H}-\mathrm{NMR}\left(\mathrm{CDCl}_{3}, 400 \mathrm{MHz}\right): \delta 7.33(\mathrm{~d}$, $J=9.6 \mathrm{~Hz}, 1 \mathrm{H}), 7.27(\mathrm{~d}, J=9.6 \mathrm{~Hz}, 1 \mathrm{H}), 6.45(\mathrm{~s}, 1 \mathrm{H}), 3.96(\mathrm{~s}$, $6 \mathrm{H}), 3.66(\mathrm{t}, J=6.4 \mathrm{~Hz}, 2 \mathrm{H}), 2.76(\mathrm{t}, J=7.6 \mathrm{~Hz}, 2 \mathrm{H}), 1.78-1.72$ (m, 2H), 1.61-1.25 (m, 6H); ${ }^{13} \mathrm{C} \mathrm{NMR}\left(\mathrm{CDCl}_{3}, 150 \mathrm{MHz}\right): \delta$ 181.76 (C-1), 181.74 (C-4), 154.4 (C-5), 154.3 (C-8), 153.7 (C-2), 127.5 (C-3), 121.0 (C-7), 120.91 (C-6), 120.91 (C-10), $119.6(\mathrm{C}-9), 56.8\left(\mathrm{OCH}_{3}\right), 56.5\left(\mathrm{OCH}_{3}\right), 56.9\left(\mathrm{C}-1^{\prime}\right), 32.3(\mathrm{C}-$ $\left.2^{\prime}\right), 31.9\left(\mathrm{C}-3^{\prime}\right), 31.4\left(\mathrm{C}-4^{\prime}\right), 30.4\left(\mathrm{C}-5^{\prime}\right), 30.2\left(\mathrm{C}-6^{\prime}\right) ; \mathrm{m} / z$ $372.9(M+\mathrm{Na})^{+}$.

3.2. HEDMNQ and HHDMNQ Inhibit Lung Cancer Cell Proliferation. To determine the cell cytotoxicity after HEDMNQ and HHDMNQ treatment, cell viabilities were measured by using the CCK-8 assay. As shown in Figures 2(a) and 2(c), HEDMNQ and HHDMNQ significantly inhibited the growth of A549, NCI-H23, and NCIH460 non-small-cell lung cancer cells in a dose- and timedependent manner, and the $\mathrm{IC}_{50}$ values of Shikonin, 5-FU, HEDMNQ, and HHDMNQ for each cell line are shown in Table 1. As shown in Figures 2(b) and 2(d), HEDMNQ and HHDMNQ had significantly lower cytotoxicity compared with shikonin and 5-FU in normal lung IMR-90, liver L-02, and stomach GES-1 cells. These data indicated that HEDMNQ and HHDMNQ selectively inhibited the viability of lung cancer cells with less cytotoxic effects on nonmalignant cells. In addition, HHDMNQ had the stronger inhibitory effects on cell viability, and compared with other cells, the A549 cells have a lower $\mathrm{IC}_{50}$ value and more sensitive to HHDMNQ, so we chose them for further study.

3.3. HHDMNQ Induces Cell Cycle Arrest at the G2/M Phase in A549 Cells. To assess the effect of HHDMNQ on cell cycle distribution, A549 cells were treated with HHDMNQ for 3, 6 12 , and $24 \mathrm{~h}$. The percentage of cells at the $G_{0} / G_{1}$ phase was decreased and that at the G2/M phase was increased in a time-dependent manner. Next, we detected the G2/M phaserelated proteins to evaluate HHDMNQ-induced cell cycle arrest (Figure 3(a)). The expression levels of p21 and p27 were increased, and those of cyclin B1 and cyclin-dependent 
<smiles>COc1ccc(OC)cc1</smiles>

a. $\mathrm{AlCl}_{3}, \mathrm{NaCl}, 155^{\circ} \mathrm{C}-175^{\circ} \mathrm{C}$;

b. $\mathrm{C}_{2} \mathrm{H}_{6} \mathrm{O}_{4} \mathrm{~S}, \mathrm{NaOH}, \mathrm{Na}_{2} \mathrm{~S}_{2} \mathrm{O}_{4}, 12 \mathrm{~h}$;

c. $\mathrm{CAN}$ (cerium ammonium nitrate), $\mathrm{CH}_{3} \mathrm{CN}, \mathrm{CHCl}_{3}, \mathrm{rt}, 1 \mathrm{~h}$; d. HS-R, $\mathrm{Na}_{2} \mathrm{Cr}_{2} \mathrm{O}_{7}, \mathrm{H}_{2} \mathrm{SO}_{4}, \mathrm{MeOH}, \mathrm{rt}, 4$ h.

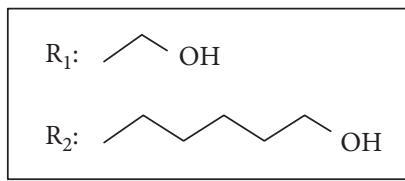

(a)
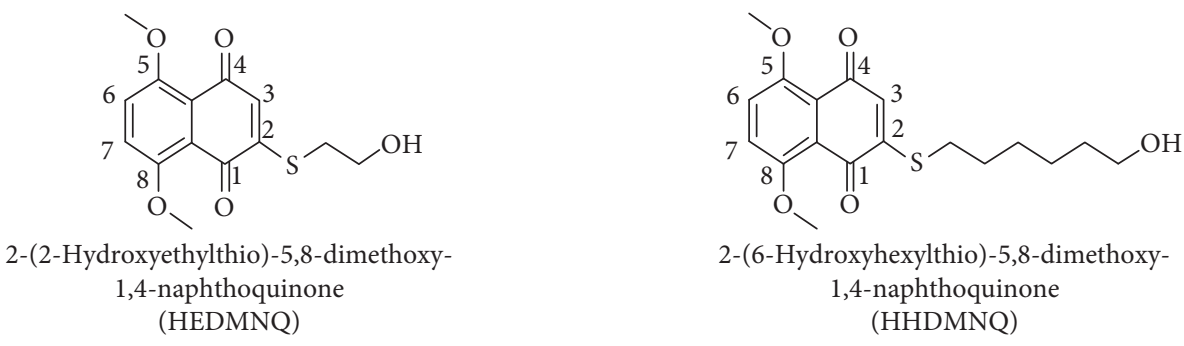

2-(6-Hydroxyhexylthio)-5,8-dimethoxy1,4-naphthoquinone (HHDMNQ)

(b)

FIgURE 1: Synthesis of 1,4-naphthoquinone derivatives HEDMNQ and HHDMNQ. (a) Reagents and conditions of HEDMNQ and HHDMNQ. (b) Chemical structures of HEDMNQ and HHDMNQ.

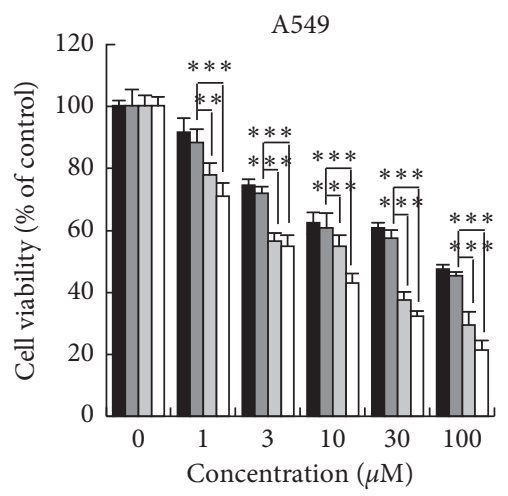

$\begin{array}{ll}\square \text { Shikonin } & \square \text { HEDMNQ } \\ \square \text { 5-FU } & \square \text { HHDMNQ }\end{array}$

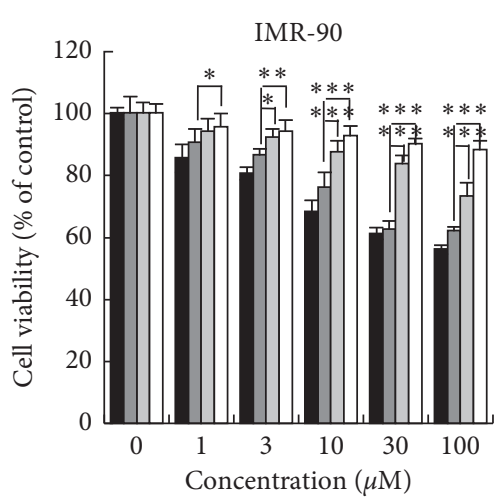

Shikonin $\square$ HEDMNQ

$\square$ 5-FU $\square$ HHDMNQ
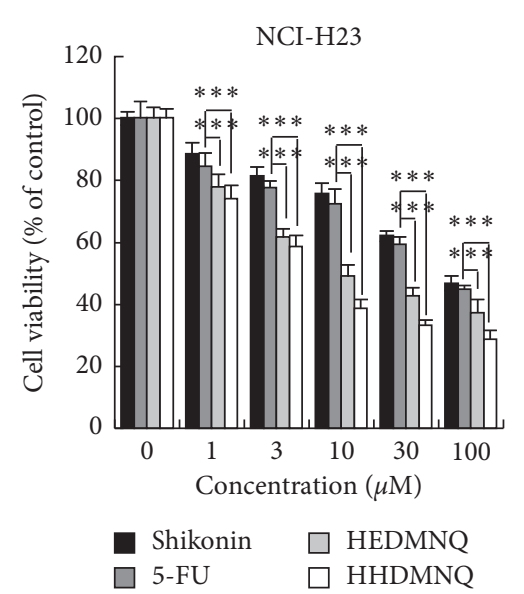

(a)
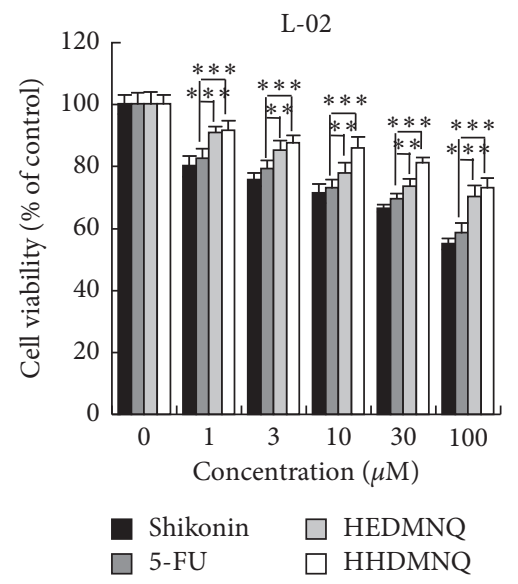

(b)

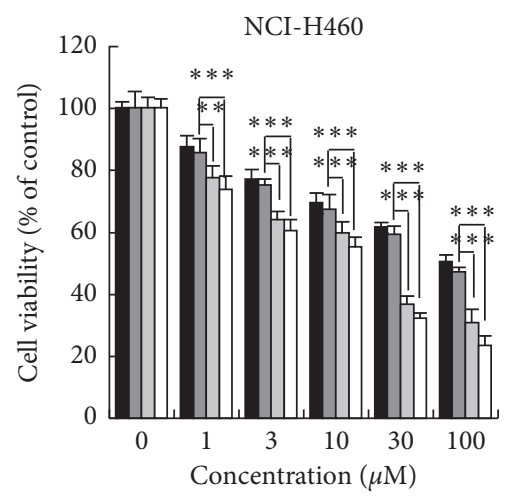

口 Shikonin $\square$ HEDMNQ $\square$ 5-FU $\square$ HHDMNQ

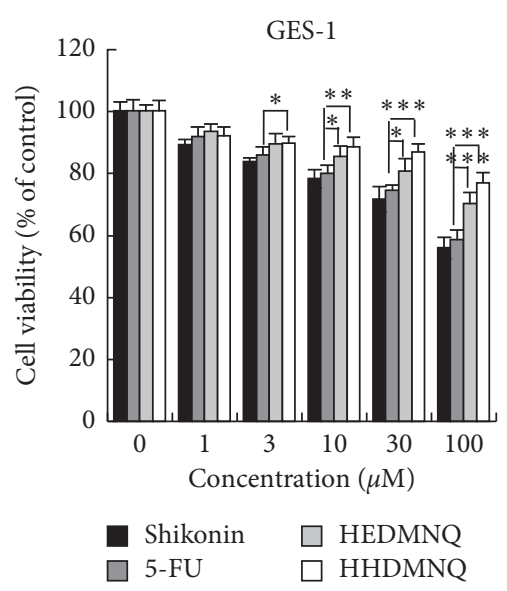

Figure 2: Continued. 

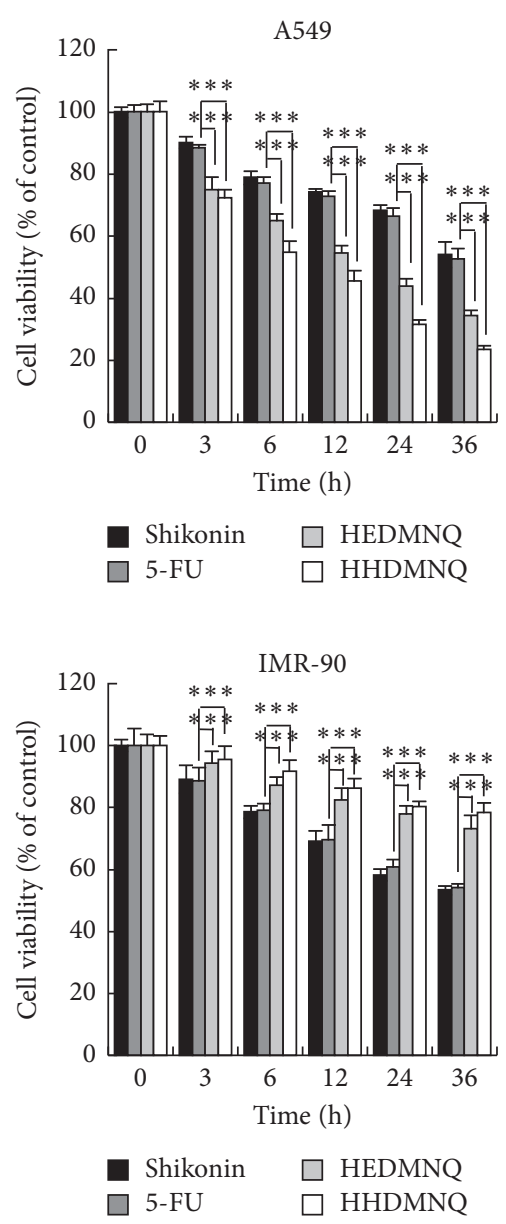

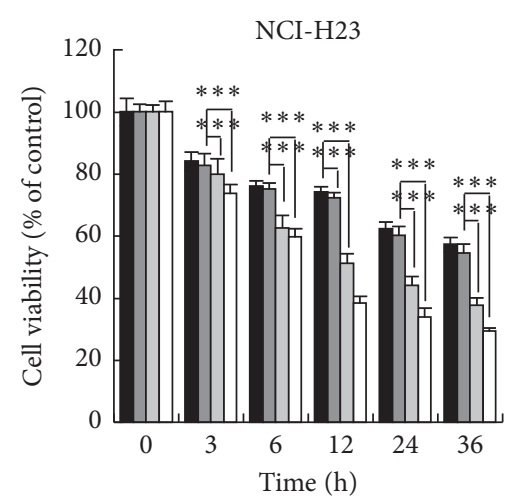

Shikonin $\square$ HEDMNQ
5-FU

(c)

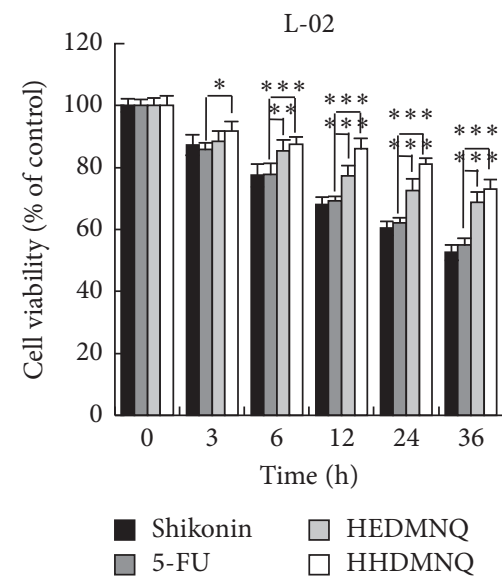

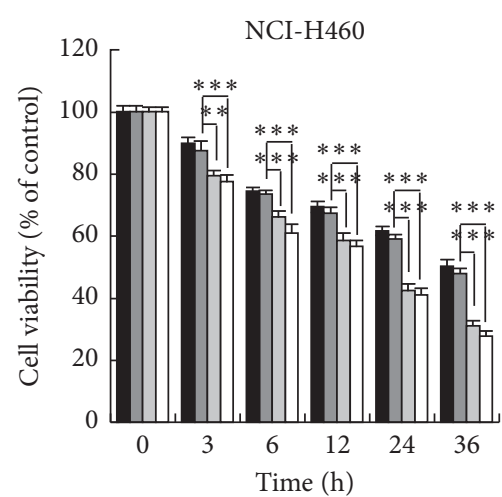

$\square$ Shikonin
$\square$ 5-FU HEDMNQ

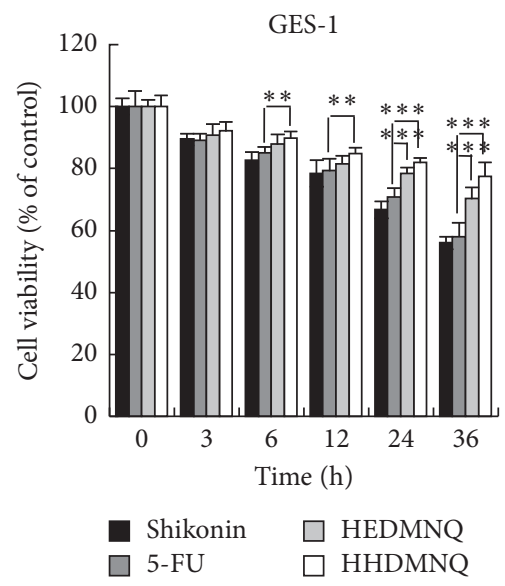

(d)

FIgURE 2: Effects of HEDMNQ and HHDMNQ on cell growth in human lung cancer cells. (a) Cell viabilities of A549, NCI-H23, and NCIH460 cells. (b) Cell viabilities of normal lung IMR-90, liver L-02, and stomach GES-1 cells. Cells were seeded in 96-well plates and treated with different concentrations of shikonin, 5-FU, HEDMNQ, and $\operatorname{HHDMNQ}(0,1,3,10,30$, and $100 \mu \mathrm{M})$ for $24 \mathrm{~h}$, and then the cell viabilities were determined by the CCK-8 assay. (c) Cell viabilities of A549, NCI-H23, and NCI-H460 cells. (d) Cell viabilities of normal lung IMR-90, liver L-02, and stomach GES-1 cells. Cells were seeded in 96-well plates and treated with shikonin, 5-FU, HEDMNQ, and HHDMNQ for 3, $6,12,24$, and $36 \mathrm{~h}$, and then the cell viabilities were determined by the CCK- 8 assay. Data were collected from three individual experiments $\left({ }^{*} p<0.05,{ }^{* *} p<0.01,{ }^{* * *} p<0.001\right)$.

TABLE 1: $\mathrm{IC}_{50}$ values of shikonin, 5-FU, HEDMNQ, and HHDMNQ in lung cancer cells.

\begin{tabular}{lcccc}
\hline Cell name & Shikonin $(\mu \mathrm{M})$ & 5-FU $(\mu \mathrm{M})$ & HEDMNQ $(\mu \mathrm{M})$ & HHDMNQ $(\mu \mathrm{M})$ \\
\hline A549 & $52.83 \pm 2.02$ & $52.83 \pm 2.02$ & $10.91 \pm 1.22$ & $5.62 \pm 2.16$ \\
NCI-H23 & $71.55 \pm 2.35$ & $69.31 \pm 3.39$ & $14.78 \pm 2.31$ & $6.62 \pm 1.65$ \\
NCI-H460 & $79.19 \pm 2.12$ & $74.14 \pm 1.84$ & $14.22 \pm 2.06$ & $9.07 \pm 1.38$ \\
\hline
\end{tabular}

kinase $1 / 2(\mathrm{CDK} 1 / 2)$ were decreased (Figure 3(b)). These results suggested that HHDMNQ arrested the cell cycle at the G2/M phase concomitantly with the downregulation of cyclin B1 and CDK1/2 in A549 cells.

3.4. HHDMNQ Induces Apoptosis in A549 Cells. To assess whether the suppressed cell viability effects of HHDMNQ were associated with apoptosis, A549 lung cancer cells were stained with Hoechst 33342 and PI. As shown in Figure 4(a), after treatment with HHDMNQ, nuclear chromatin condensation and fragmented punctuate blue and red nuclear fluorescence were observed in A549 cells in a time-dependent manner, similar to morphological changes in the apoptotic cells. To further assess the apoptosis caused by HHDMNQ, the apoptosis rate of A549 cells was examined by flow cytometry. HHDMNQ triggered the apoptosis of A549 cells, starting at $12 \mathrm{~h}$, in a time-dependent manner (Figure 4(b)). These results suggested that HHDMNQ could induce the apoptosis of lung cancer A549 cells. Since 

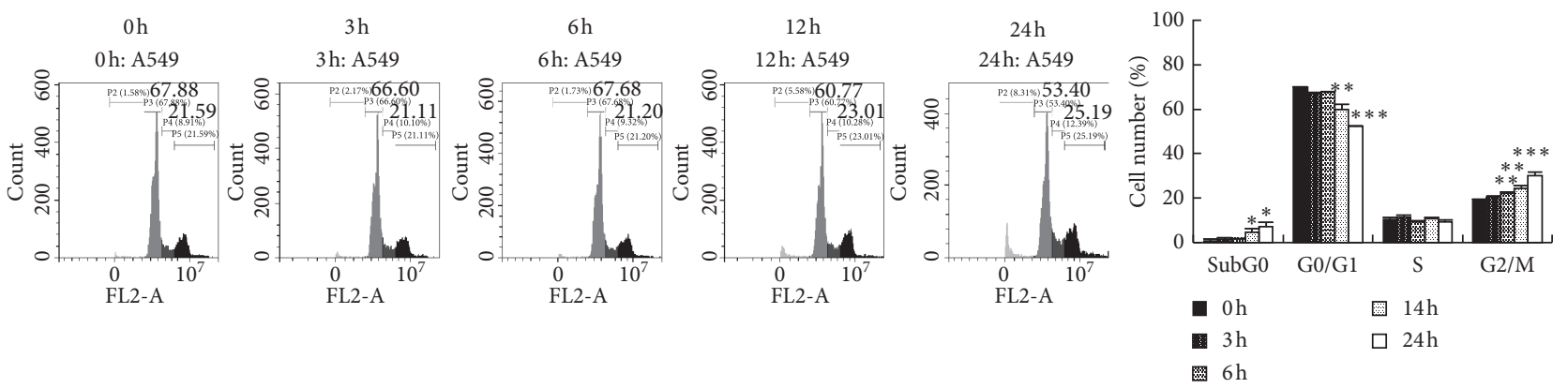

(a)
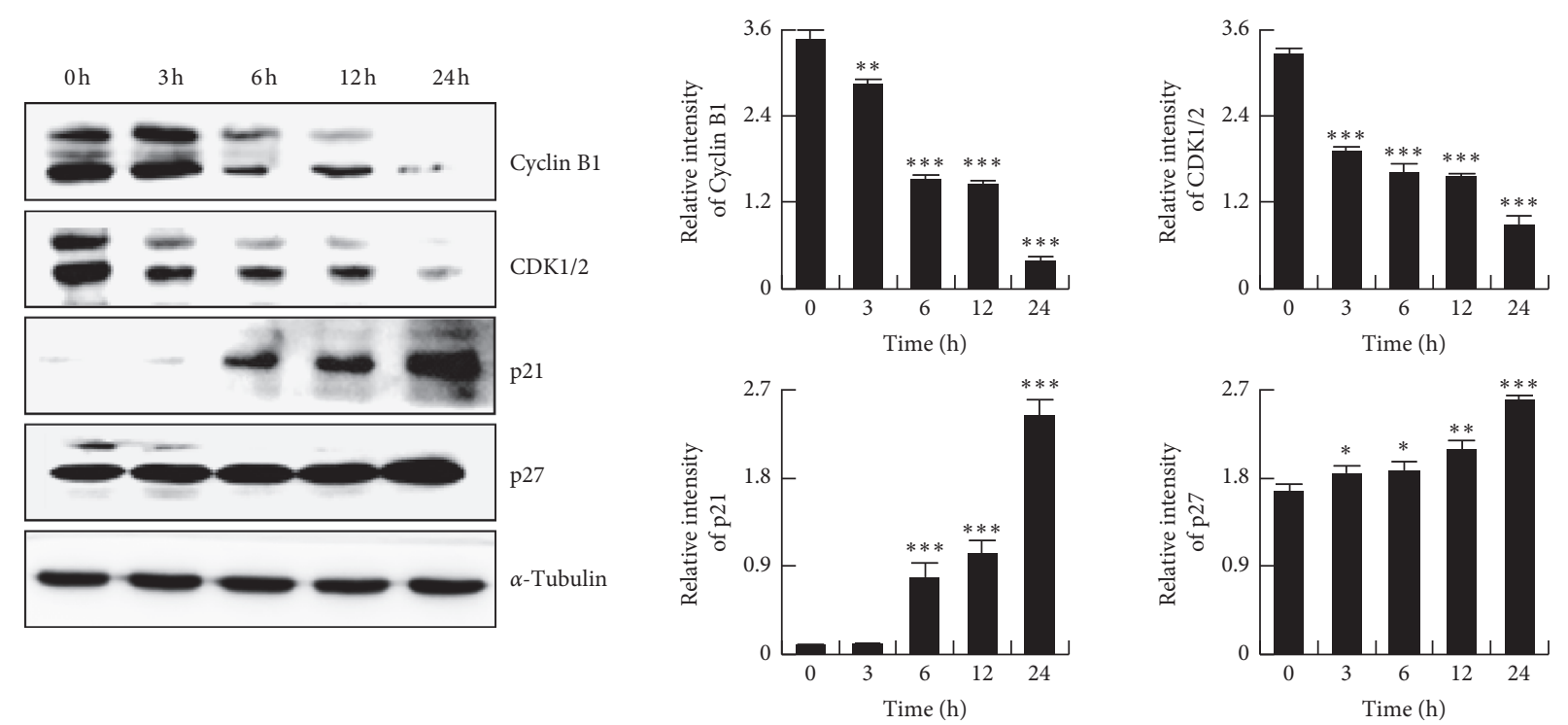

(b)

Figure 3: Effects of HHDMNQ treatment $(3,6,12$, and $24 \mathrm{~h}$ ) on the A549 cell cycle. (a) Cells were stained with PI, and the cell cycle distribution was determined by flow cytometry and quantitative cell cycle analysis. (b) The expression levels of CDK1/2, cyclin B1, p21, and p27 proteins were analyzed by western blot and quantitative histograms of proteins $\left({ }^{*} p<0.05,{ }^{* *} p<0.01,{ }^{* * *} p<0.001\right)$.
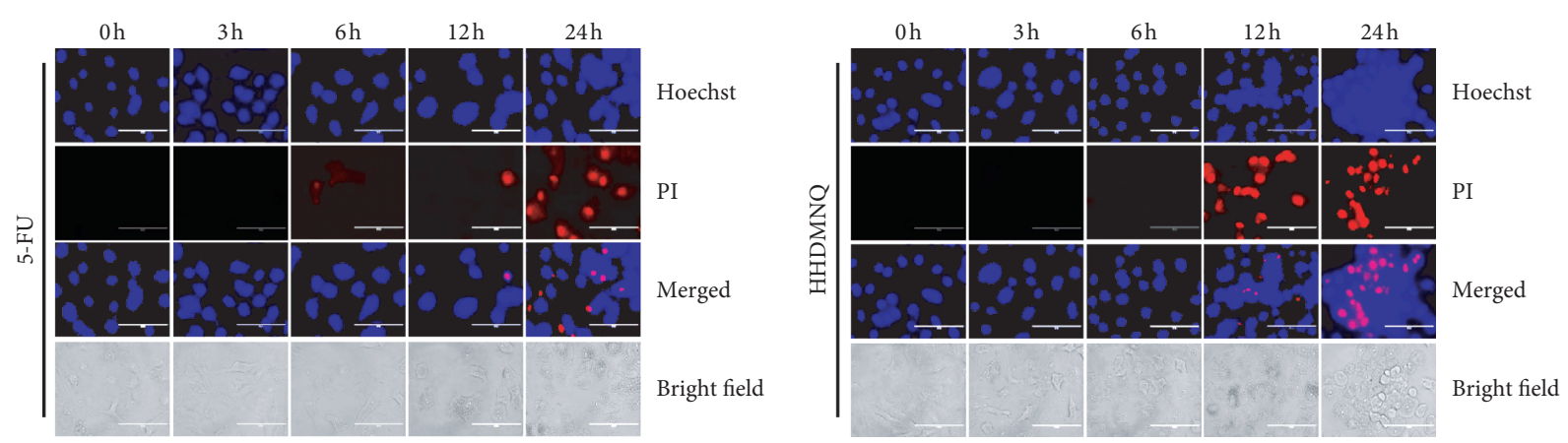

(a)
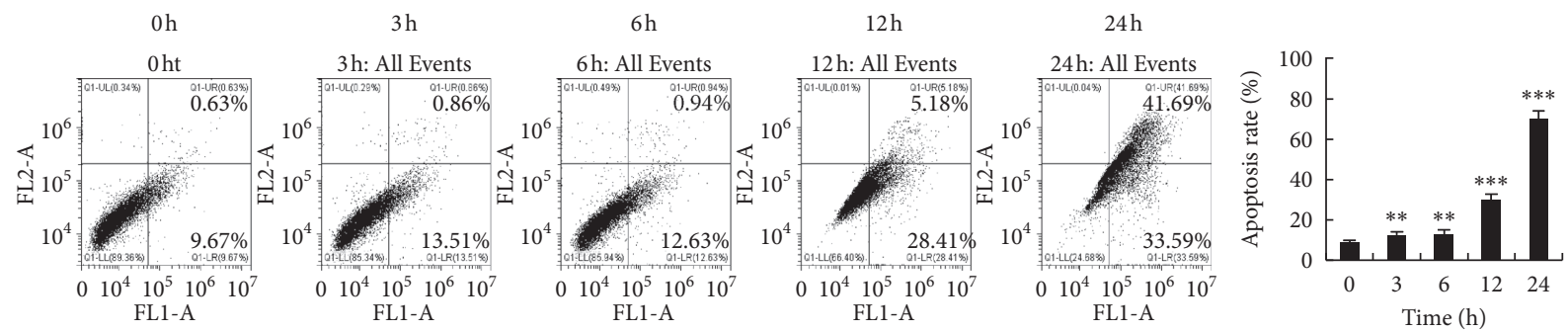

(b)

Figure 4: Continued. 

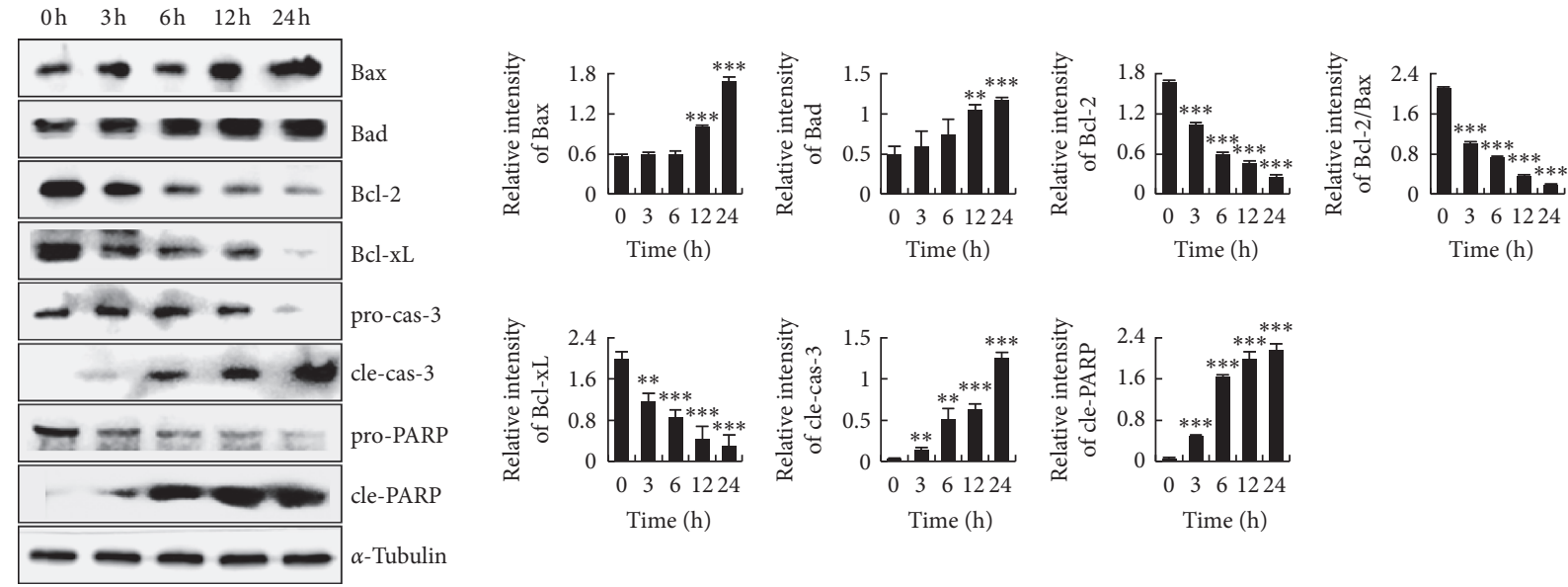

(c)

FigURE 4: Effects of HHDMNQ on the morphological changes, apoptosis rate, and intrinsic apoptosis pathway in A549 cells. (a) A549 cells treated with $6 \mu \mathrm{M}$ 5-FU or HHDMNQ for 3, 6, 12, and $24 \mathrm{~h}$ fluorescence microscopic images (magnification, 200×) and relative fluorescence intensity. (b) Apoptosis distribution of A549 cells was determined by Annexin V-FITC/PI staining and quantification of early and late apoptotic cells. (c) A549 cells treated with $6 \mu \mathrm{M}$ HHDMNQ for 3, 6, 12, and $24 \mathrm{~h}$. Expression levels of Bax, Bad, Bcl-2, Bcl-xL, pro-caspase-3, cleaved caspase-3, pro-PARP, cleaved PARP, and Bcl-2/Bax ratio were analyzed by western blot and quantitative histograms of proteins $\left({ }^{*} p<0.05,{ }^{* *} p<0.01,{ }^{* * *} p<0.001\right)$.

HHDMNQ could induce apoptosis of A549 cells, we examined apoptosis-related proteins by western blot. As shown in Figure 4(c), the expression levels of Bcl-2-associated $X$ protein (Bax), Bcl-2-associated death promoter (Bad), cleaved caspase-3, and cleaved PARP were increased after treatment with HHDNMQ, whereas the expression levels of the anti-apoptotic proteins B-cell lymphoma 2 (Bcl$2)$, B-cell lymphoma-extra-large (Bcl-xL), pro-caspase-3, pro-poly (ADP-ribose) polymerase (PARP), and Bcl-2/Bax ratio were significantly decreased in a time-dependent manner. These results illustrated that HHDMNQ activated the mitochondria-dependent pathway to induce apoptosis in A549 lung cancer cells.

3.5. HHDMNQ Regulates the MAPK, STAT3, and NF- $\kappa B$ Signalling Pathways in A549 Cells. To investigate the underlying mechanisms of HHDMNQ-induced apoptosis in lung cancer cells, the key proteins in the MAPK, STAT3, and $\mathrm{NF}-\kappa \mathrm{B}$ signalling pathways were examined. As shown in Figures 5(a)-5(e), HHDMNQ treatment inhibited the activation of p-ERK, p-STAT3 (Tyr 705) and NF- $\kappa$ B (p65) but promoted the expression of $\mathrm{p}-\mathrm{p} 38, \mathrm{p}-\mathrm{JNK}$, and $\mathrm{I} \kappa \mathrm{B}-\alpha$ in a time-dependent manner. These results indicated that regulating MAPK, STAT3, and NF- $\kappa \mathrm{B}$ activity may promote HHDMNQ-mediated induction of cell apoptosis in lung cancer.

3.6. HHDMNQ Induces Oxidative Stress-Mediated Apoptosis in A549 Cells. To determine whether intracellular ROS levels are associated with activation of the programmed cell apoptosis mechanism in lung cancer cells, the levels of ROS and cell apoptosis were determined. As shown in Figure 6(a), the levels of ROS were significantly increased in a timedependent manner after treating A549 cells with HHDMNQ for 3, 6, 12, and $24 \mathrm{~h}$. As shown in Figure 6(b), intracellular ROS levels were suppressed after pretreatment with the specific ROS inhibitor NAC. To demonstrate whether HHDMNQ-induced increases in ROS were associated with the apoptosis of A549 cells, cell apoptosis-related proteins were determined. As shown in Figure 6(c), NAC significantly reversed the increased expression levels of Bax, Bad, cleaved caspase- 3 , and cleaved PARP and the decreased the expression levels of $\mathrm{Bcl}-2, \mathrm{Bcl}-\mathrm{xL}$, pro-caspase-3, and proPARP. These findings demonstrated that HHDMNQ increased intracellular ROS levels, resulting in A549 cell apoptosis.

3.7. HHDMNQ Induces Apoptosis through ROS-Mediated MAPK, STAT3, and NF- $\kappa$ B Signalling Pathways in A549 Cells. To demonstrate the underlying molecular mechanism of HHDMNQ-induced ROS-mediated apoptosis of A549 cells, we examined the effects of HHDMNQ on MAPK, STAT3, and $\mathrm{NF}-\kappa \mathrm{B}$ signalling pathways that play pivotal roles in cancer cells. As shown in Figures 7(a)-7(e), the expression levels of $\mathrm{p} 38, \mathrm{JNK}$, and $\mathrm{I} \kappa \mathrm{B}-\alpha$ were increased and those of ERK, STAT3, and NF- $\kappa$ B were decreased after HHDMNQ treatment. However, the expression levels of proteins were reversed in the HHDMNQ and NAC treatment groups. These results indicated that HHDMNQ induced A549 cell apoptosis by regulating ROS-mediated MAPK, STAT3, and $\mathrm{NF}-\kappa \mathrm{B}$ signalling pathways.

\section{Discussion}

There is an urgent need to develop novel anticancer drugs, and inhibition of proliferation and induction of apoptosis in cancer cells are the potential therapeutic strategies for drug development [24]. The 1,4-naphthoquinone pharmacophore 


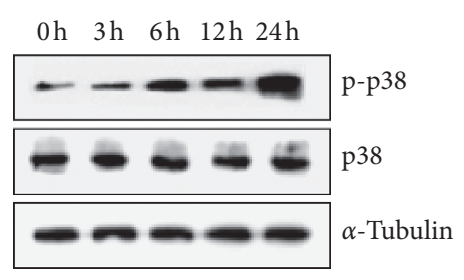

(a)

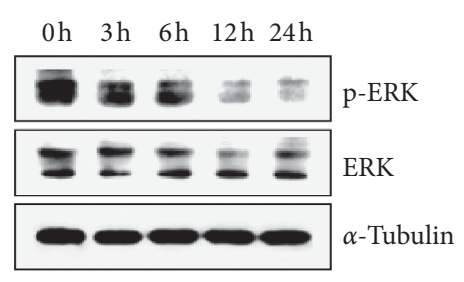

(b)
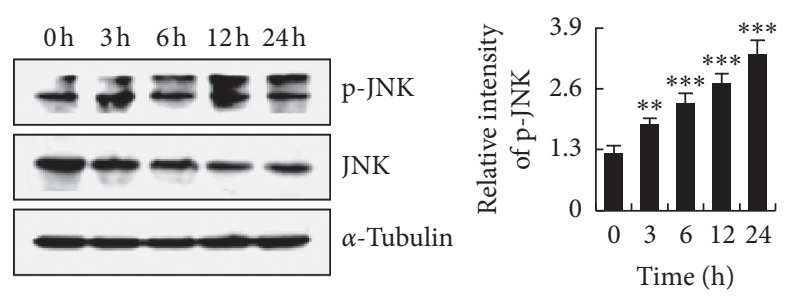

(c)
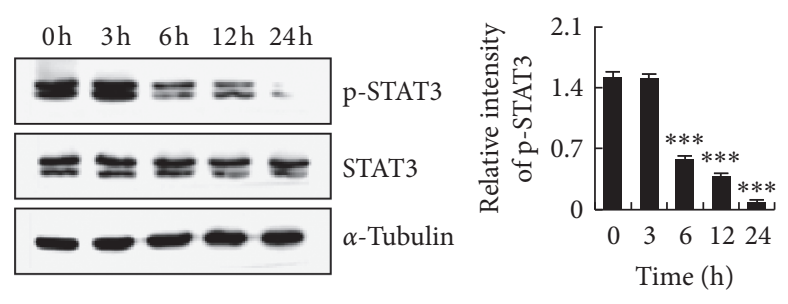

(d)
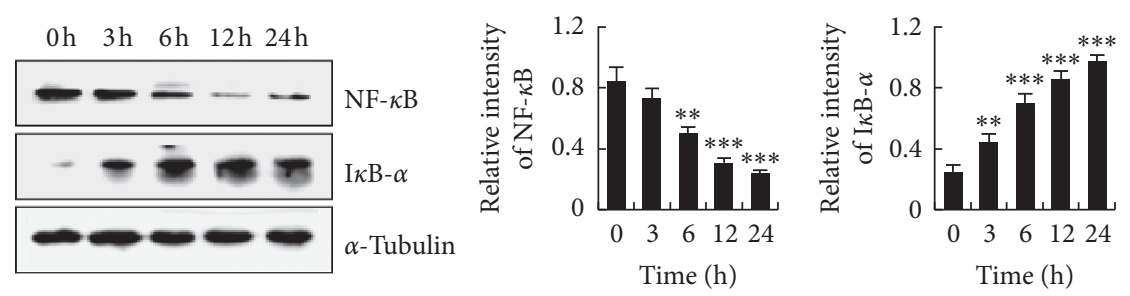

(e)

FIGURE 5: Effects of HHDMNQ on the MAPK, STAT3, and NF- $\kappa$ B signalling pathways in A549 cells. (a-e) A549 cells treated with $6 \mu \mathrm{M}$ HHDMNQ for 3, 6, 12, and $24 \mathrm{~h}$. Expression levels of p38, ERK, JNK, STAT3, NF- $\kappa$ B (p65), and I $\kappa$ B- $\alpha$ were analyzed by western blot and quantification histograms of proteins $\left({ }^{*} p<0.05,{ }^{* *} p<0.01,{ }^{* * *} p<0.001\right)$.

has growth inhibitory activity and can induce apoptosis and anti-inflammation in various cancer cell lines. Furthermore, the side chain can influence the entire activity of 1,4naphthoquinone derivatives [25]. In this study, we used 1,4naphthoquinone as a pharmacophore to synthesize the novel naphthoquinone derivatives HEDMNQ and HHDMNQ. The 1,4-naphthoquinone derivatives suppressed the growth of lung cancer cells with the lower $\mathrm{IC}_{50}$ values and lower cytotoxicity in normal cell lines. HHDMNQ had higher efficiency and lower cytotoxicity than HEDMNQ.
Furthermore, HHDMNQ induced cell cycle arrest at the G2/M phase by regulating the CDK/cyclin complex in A549 lung cancer cells.

Induction of cell apoptosis is a crucial physiological process to inhibit cancer cell proliferation. In addition, cell apoptosis is related to the promotion of pro-apoptotic proteins and the suppression of anti-apoptotic proteins, and the $\mathrm{Bcl}-2$ family is foremost in regulating the mitochondrial pathway [26]. In this study, fluorescence microscopy showed A549 cell shrinkage, deformation, and shedding; and flow 

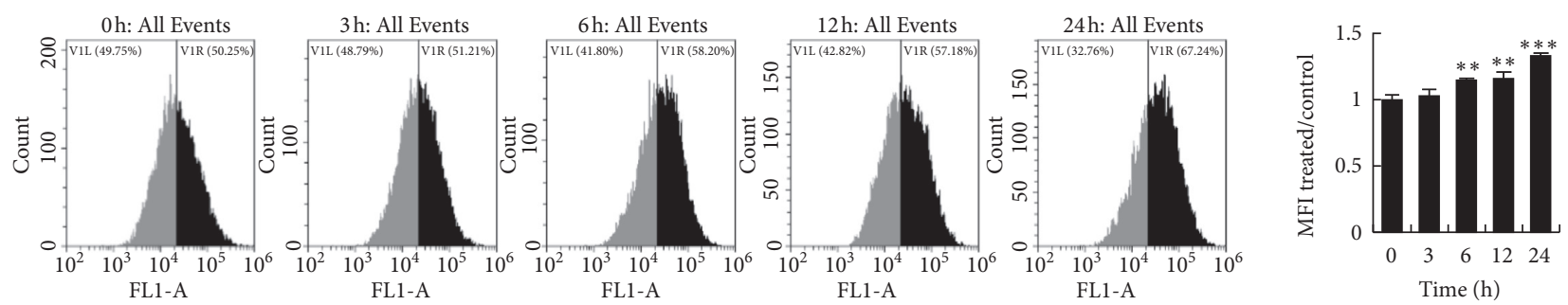

(a)

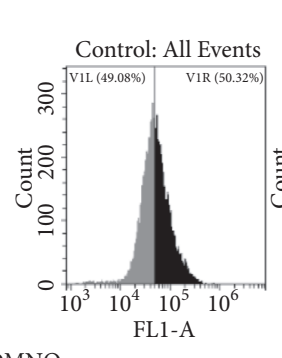
HHDMNQ NAC

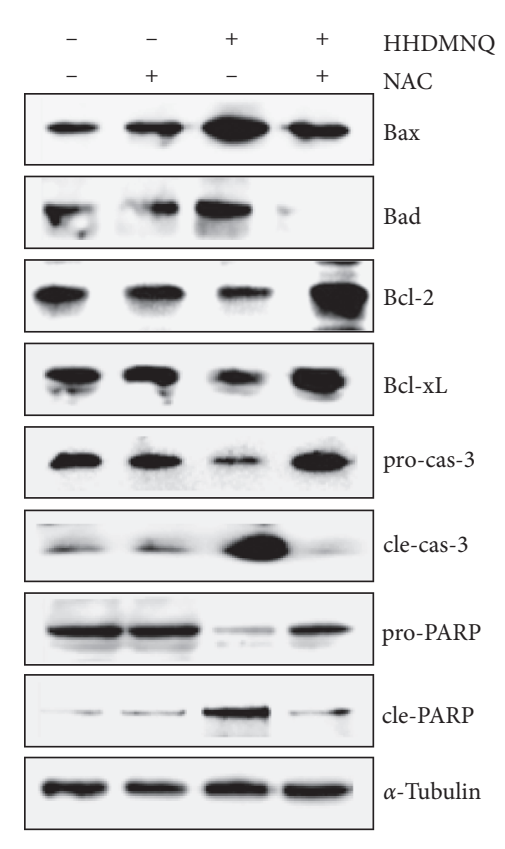

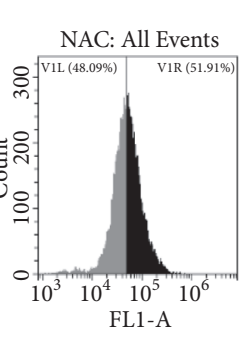

$+$

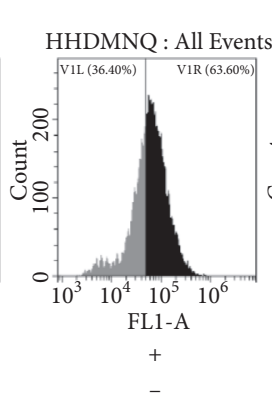

(b)
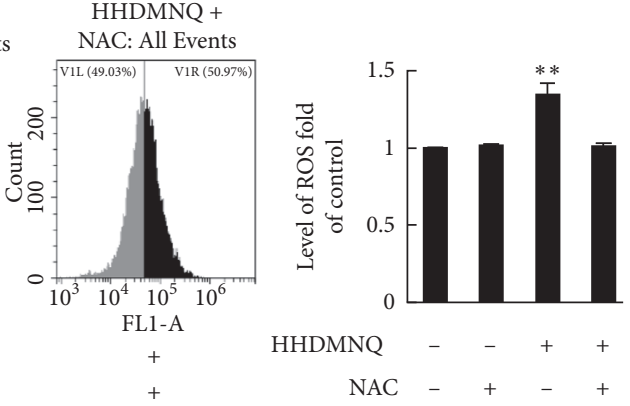

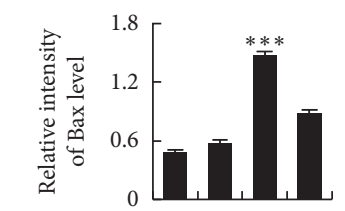

HHDMNQ NAC

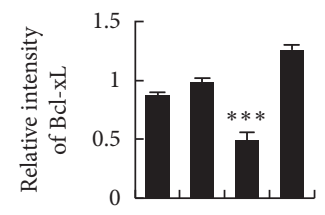

HHDMNQ NAC

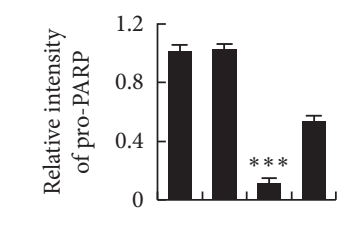

HHDMNQ

NAC

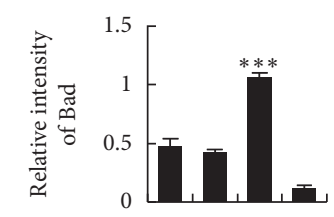

HHDMNQ

NAC

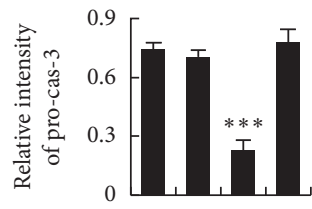

HHDMNQ

NAC

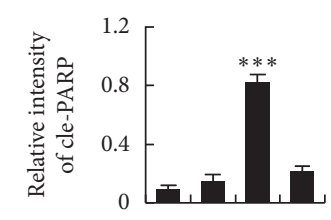

HHDMNQ

NAC

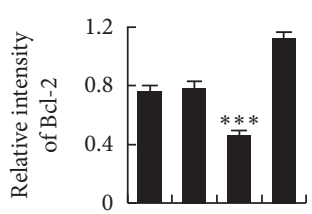

HHDMNQ $\quad-\quad+\quad+$ NAC -+-+

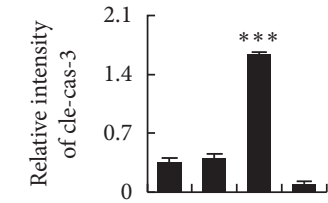

HHDMNQ

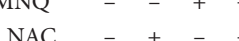

(c)

FiguRE 6: Effects of HHDMNQ on intracellular ROS levels and mitochondrial pathways in A549 cells. (a) A549 cells treated with $6 \mu \mathrm{M}$ HHDMNQ for 3, 6, 12, and $24 \mathrm{~h}$, and intracellular ROS levels were measured by flow cytometry and quantification histograms of intracellular ROS levels. (b) A549 cells treated with or without NAC for $24 \mathrm{~h}$, and intracellular ROS levels were measured by flow cytometry and quantification histograms of intracellular ROS levels. (c) A549 cells treated with or without NAC for $24 \mathrm{~h}$; expression levels of Bax, Bad, Bcl-2, Bcl-xL, caspase-3, and PARP were measured by western blot and quantitative histograms of proteins $\left({ }^{*} p<0.05,{ }^{* *} p<0.01\right.$, $\left.{ }^{* * *} p<0.001\right)$.

cytometry results showed that early apoptotic and late apoptotic cells were increased after HHDMNQ treatment in a time-dependent manner. Furthermore, HHDMNQ promoted the downregulation of $\mathrm{Bcl}-2$ and $\mathrm{Bcl}-\mathrm{xL}$ and the upregulation of Bad, Bax, cleaved caspase-3, and cleaved
PARP in A549 cells. Thus, it can be considered that HHDMNQ-mediated induction of A549 lung cancer cell apoptosis is associated with regulation of the mitochondriaregulated apoptosis pathway. In addition, some studies suggested that the mutant p53 could promote cancer cell 

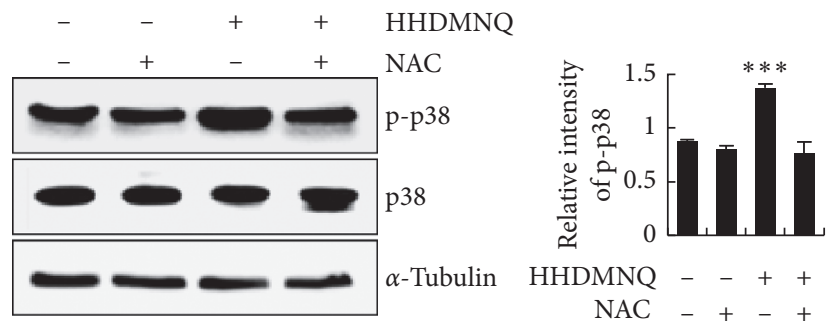

(a)
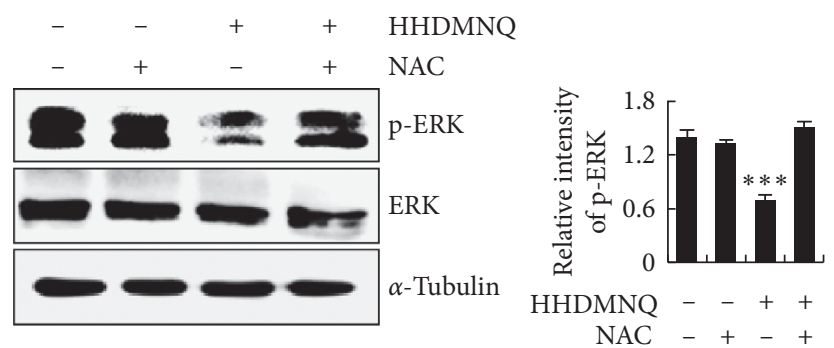

(b)
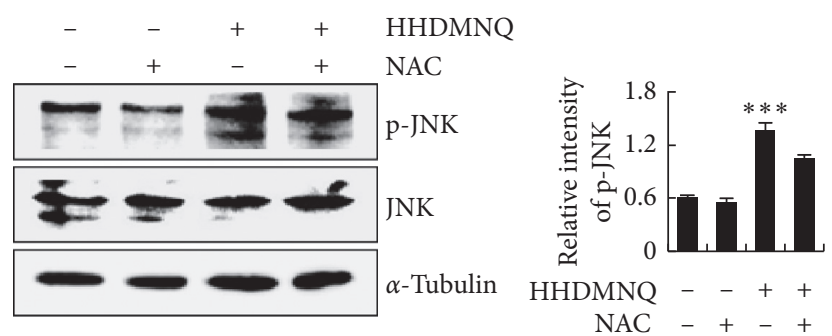

(c)

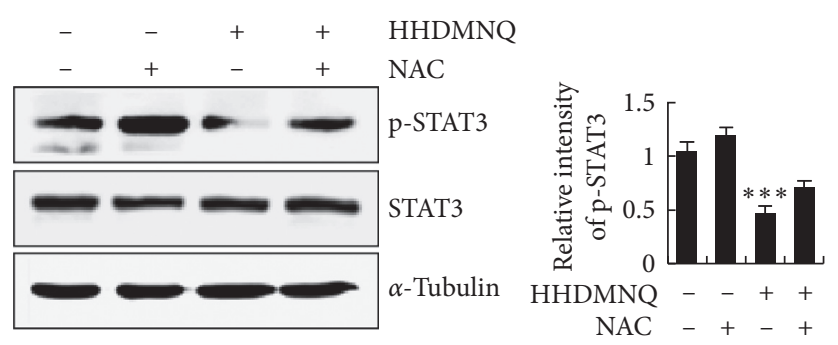

(d)
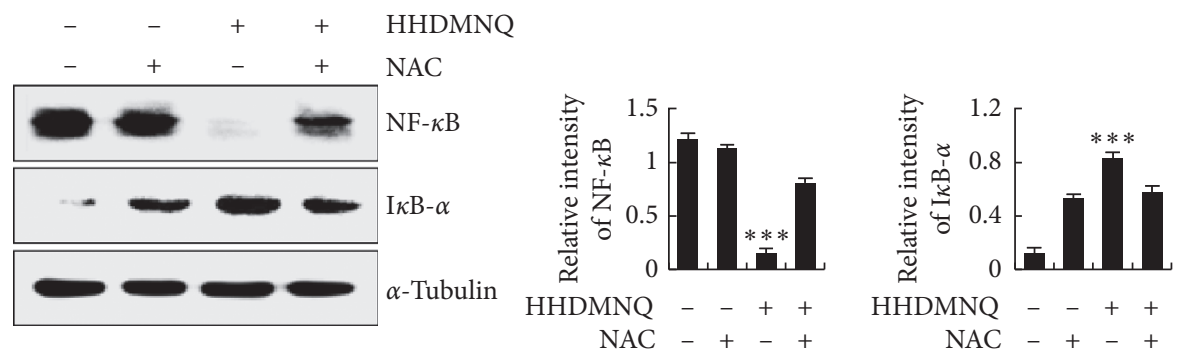

(e)

FIGURE 7: Effects of NAC on HHDMNQ-induced oxidative stress for apoptosis in A549 cells. (a-e) Expression levels of p38, ERK, JNK, STAT3, NF- $\kappa \mathrm{B}$, and I $\kappa \mathrm{B}-\alpha$ were analyzed by western blot and quantitative histograms of proteins $\left({ }^{*} p<0.05,{ }^{* *} p<0.01,{ }^{* * *} p<0.001\right)$.

proliferation, invasion, and drug resistance, and the wildtype p53 could mediate various cellular activities, such as promote cell cycle arrest and apoptosis by inhibiting the phosphorylation of STAT3 and regulating the expression of cell cycle target genes $[27,28]$. It has been shown that 2 (naphthalene-2-thio)-5,8-dimethoxy-1,4-naphthoquinone could induce G0/G1 phase arrest by regulating the wild-type p53 in cancer cells [29]. The structures of 2-(naphthalene-2- 


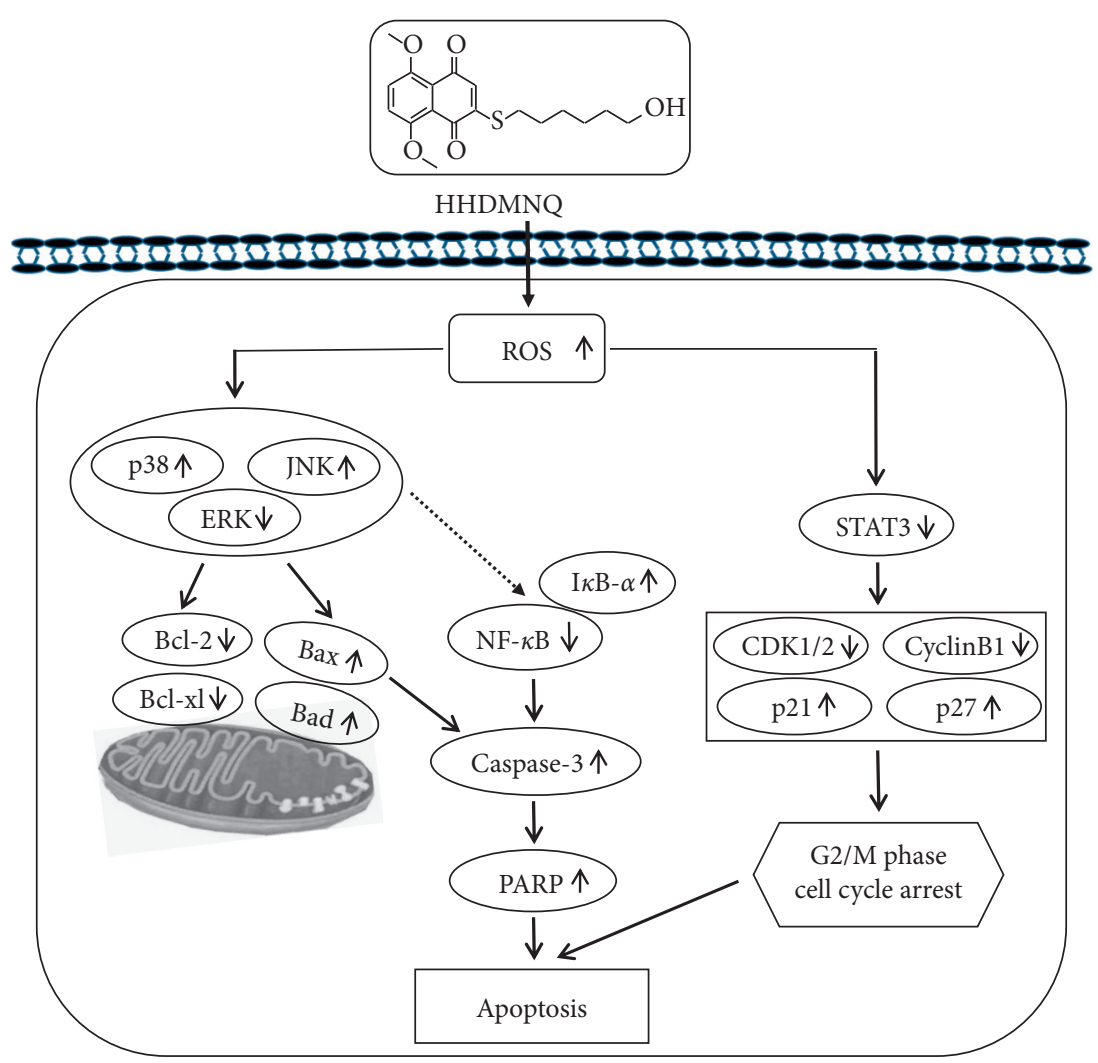

Figure 8: Schematic mechanisms illustration of HHDMNQ-induced apoptosis in lung cancer A549 cells. The molecular mechanisms of HHDMNQ anticancer activity as related to the ROS generation and MAPK/STAT3/NF- $\kappa$ B pathways.

thio)-5,8-dimethoxy-1,4-naphthoquinone are similar to the compound that we synthesized. On the basis of the above, we speculate that HHDMNQ induced cell apoptosis and G2/M cell cycle arrest may be related to p53 expression.

Developing anticancer agents that modulate inflammatory signalling pathways and cell proliferation may be a rational strategy for preventing or treating lung cancers. It has been demonstrated that ERK, JNK, and p38 are the three main components of the MAPK signalling pathway, and they play an important regulatory role in cancer cell apoptosis [30]. ERK is a key protein kinase in the MAPK family, whose abnormal activation will cause the proliferation and invasion of various tumor cells. The results indicated that paxillin promoted $\mathrm{Bcl}-2$ activation by mediating ERK activation, which was associated with tumor formation efficacy in mice [31]. The Janus kinase (JAK)/STAT signalling pathway is one of the important signalling pathways in modulating cell proliferation, differentiation, migration, and apoptosis [32]. STAT3 maintains an abnormal activation state, which can accelerate the cycle process by controlling the protein levels of cyclin $D, \mathrm{p} 21$, and $\mathrm{p} 27$, promoting the new blood vessels generation and providing supplementary nutrition for the development of cancer cells. Some studies suggested that celecoxib induced apoptosis and cell cycle arrest via inhibition of STAT3 phosphorylation in NPC cells $[33,34]$. The NF- $\kappa$ B signalling pathway is associated with the growth and survival of cancer cells [35]. I $\kappa \mathrm{B}-\alpha$ is an important factor in the NF- $\kappa \mathrm{B}$ family of inhibitors, whose phosphorylation is closely related to NF- $\kappa \mathrm{B}$ activation. The phosphorylation of $\mathrm{I} \kappa \mathrm{B}-\alpha$ will result in the ubiquitinproteasome system degradation, producing amounts of NF$\kappa \mathrm{B}$ dimers, while inhibition of the phosphorylation leads to the inactivation of NF- $\kappa \mathrm{B}$. And the inhibition effects on NF$\kappa \mathrm{B}$ activation caused the ratio of $\mathrm{Bax} / \mathrm{Bcl}-2$ upregulated in the Bcl-2 family and then promoted the activation of caspase-3 [36, 37]. In this study, we examined whether HHDMNQ treatment regulates the MAPK, STAT3, and NF$\kappa \mathrm{B}$ signalling pathways. We found that HHDMNQ efficiently promoted the phosphorylation of $\mathrm{p} 38$ and JNK and inhibited the phosphorylation of ERK, STAT3, NF- $\kappa$ B and $\mathrm{I} \kappa \mathrm{B}-\alpha$ in a time-dependent manner. The MAPK, STAT3 and NF- $\kappa$ B signalling pathways were inhibited by HHDMNQ, and they were closely associated with the suppression of proliferation and induction of A549 lung cancer cell apoptosis.

Oxidative stress regulates cancer cell apoptosis by activating multifarious redox signalling cascade reactions [38]. The mitochondrial pathway is the main component of the intrinsic apoptosis mechanism, and it is the main target of ROS. The Bcl-2 family of proteins and caspases is the characteristic feature of ROS-mediated mitochondrial-induced apoptosis in cancer cells [39]. Numerous smallmolecule compounds have been shown to stimulate excessive ROS production, and they are associated with the induction of cell apoptosis. In this study, HHDMNQ promoted the accumulation of ROS in A549 cells in a time- 
dependent manner, and pretreatment with NAC restored the levels of ROS. HHDMNQ induced cell apoptosis, and the expression levels of apoptosis regulators were completely reversed by NAC pretreatment. We hypothesized that HHDMNQ could modulate MAPK, STAT3, and NF- $\kappa$ B signalling pathway activation through regulating intracellular ROS levels to induce A549 cell apoptosis. We confirmed our hypotheses by using NAC, which reversed the expression levels of MAPK, STAT3, and NF- $\kappa$ B signallingpathway-related proteins in A549 cells. Pretreatment of A549 cells with NAC not only abolished the effects of HHDMNQ-induced apoptosis but also reversed HHDMNQ-mediated suppressive effects on MAPK, STAT3, and NF- $\kappa$ B signalling pathways in A549 cells.

\section{Conclusion}

In conclusion, we synthesized the two novel types of 1,4naphthoquinone derivatives HEDMNQ and HHDMNQ. This study revealed for the first time that HHDMNQ induced mitochondria-dependent apoptosis and G2/M cell cycle arrest promoted the accumulation of ROS and mediated MAPK/STAT3/NF- $\kappa$ B signalling pathways and then regulated the downstream-related apoptosis and cycle proteins in A549 lung cancer cells (Figure 8).

\section{Data Availability}

The data used to support the findings of this study are available from the corresponding author upon request.

\section{Conflicts of Interest}

The authors declare that there are no conflicts of interest regarding the publication of this paper.

\section{Authors' Contributions}

Gui-Nan Shen, Cheng Wang, and Ying-Hua Luo contributed equally to this study as first authors.

\section{Acknowledgments}

This work was supported by the Postdoctoral Scientific Research Foundation of Heilongjiang Province of China (Grant No. LBH-Q13132), the Heilongjiang Farms and Land Reclamation Administration Support Project for Key Scientific Research (No. HKKYZD190705), the Heilongjiang Bayi Agricultural University Support Program for "San Zong" (No. TDJH201905), the Heilongjiang Touyan Innovation Team Program (No. 2019HTY078), and Research Project of Heilongjiang Bayi Agricultural University (No. XDB202012).

\section{References}

[1] A. Mathew, "Global survey of clinical oncology workforce," Journal of Global Oncology, vol. 4, pp. 4-12, 2018.

[2] S. C. Tripathi, J. F. Fahrmann, M. Celiktas et al., "MCAM mediates chemoresistance in small-cell lung cancer via the
PI3K/AKT/SOX2 signaling pathway," Cancer Research, vol. 77, no. 16, pp. 4414-4425, 2017.

[3] T. N. Zamay, G. S. Zamay, O. S. Kolovskaya et al., "Current and prospective protein biomarkers of lung cancer," Cancers (Basel), vol. 9, no. 11, pp. 155-176, 2017.

[4] O. Valencia, G. Lopes, P. Sánchez, L. Acuña, D. Uribe, and J. González, "Incidence and prevalence of cancer in Colombia: the methodology used matters," Journal of Global Oncology, vol. 4, no. 4, pp. 1-7, 2018.

[5] F. Bray, J. Ferlay, I. Soerjomataram, R. L. Siegel, L. A. Torre, and A. Jemal, "Global cancer statistics 2018: GLOBOCAN estimates of incidence and mortality worldwide for 36 cancers in 185 countries," CA: A Cancer Journal for Clinicians, vol. 68, no. 6, pp. 394-424, 2018.

[6] P. Xie, F. Horio, I. Fujii, J. Zhao, M. Shinohara, and M. Matsukura, "A novel polysaccharide derived from algae extract inhibits cancer progression via JNK, not via the p38 MAPK signaling pathway," International Journal of Oncology, vol. 52, no. 5, pp. 1380-1390, 2018.

[7] D. Li, Y. Wei, S. Xu et al., "A systematic review and metaanalysis of bidirectional effect of arsenic on ERK signaling pathway," Molecular Medicine Reports, vol. 17, no. 3, pp. 4422-4432, 2018.

[8] F. Gao and W. J. Liu, "Advance in the study on p38 MAPK mediated drug resistance in leukemia," European Review for Medical and Pharmacological Sciences, vol. 20, no. 6, pp. 1064-1070, 2016.

[9] L. Yang, Y. Zhou, Y. Li et al., "Mutations of p53 and KRAS activate NF- $\kappa \mathrm{B}$ to promote chemoresistance and tumorigenesis via dysregulation of cell cycle and suppression of apoptosis in lung cancer cells," Cancer Letters, vol. 357, no. 2, pp. 520-526, 2015.

[10] A. Maryam, T. Mehmood, H. Zhang et al., "Alantolactone induces apoptosis, promotes STAT3 glutathionylation and enhances chemosensitivity of A549 lung adenocarcinoma cells to doxorubicin via oxidative stress," Science Reports, vol. 7, no. 1, p. 6242, 2017.

[11] K. Szoltysek, A. Walaszczyk, P. Janus, M. Kimmel, and P. Widlak, "Irradiation with UV-C inhibits TNF- $\alpha$-dependent activation of the NF- $\kappa$ B pathway in a mechanism potentially mediated by reactive oxygen species," Genes to Cells, vol. 22, no. 1, pp. 45-58, 2017.

[12] M.-H. Cheng, Y.-H. Wong, C.-M. Chang et al., "B1, a novel HDAC inhibitor, induces apoptosis through the regulation of STAT3 and NF- $\kappa \mathrm{B}$," International Journal of Molecular Medicine, vol. 39, no. 5, pp. 1137-1148, 2017.

[13] D. Li, J. Sun, W. Liu et al., "Rig-G is a growth inhibitory factor of lung cancer cells that suppresses STAT3 and NF- $\kappa \mathrm{B}$," Oncotarget, vol. 7, no. 40, pp. 66032-66050, 2016.

[14] T. Mehmood, A. Maryam, X. Tian, M. Khan, and T. Ma, "Santamarine inhibits NF-KB and STAT3 activation and induces apoptosis in HepG2 liver cancer cells via oxidative stress," Journal of Cancer, vol. 8, no. 18, pp. 3707-3717, 2017.

[15] X. J. Shi, B. Yu, J. W. Wang et al., "Structurally novel steroidal spirooxindole by 241 potently inhibits tumor growth mainly through ROS-mediated mechanisms," Science Reports, vol. 6, p. $31607,2016$.

[16] M. H. Raza, S. Siraj, A. Arshad et al., "ROS-modulated therapeutic approaches in cancer treatment," Journal of Cancer Research and Clinical Oncology, vol. 143, no. 9, pp. 1789-1809, 2017.

[17] Z. Zou, H. Chang, H. Li, and S. Wang, "Induction of reactive oxygen species: an emerging approach for cancer therapy," Apoptosis, vol. 22, no. 11, pp. 1321-1335, 2017. 
[18] S.-H. Wang, C.-Y. Lo, Z.-H. Gwo et al., "Synthesis and biological evaluation of lipophilic 1,4-naphthoquinone derivatives against human cancer cell lines," Molecules, vol. 20, no. 7, pp. 11994-12015, 2015.

[19] S. K. Ghosh, A. Ganta, and R. A. Spanjaard, "Discovery and cellular stress pathway analysis of 1,4-naphthoquinone derivatives with novel, highly potent broad-spectrum anticancer activity," J Biomed Sci, vol. 25, no. 1, p. 12, 2018.

[20] W.-T. Xu, G.-N. Shen, Y.-H. Luo et al., "New naphthalene derivatives induce human lung cancer A549 cell apoptosis via ROS-mediated MAPKs, Akt, and STAT3 signaling pathways," Chemico-Biological Interactions, vol. 304, pp. 148-157, 2019.

[21] C. Liu, G.-N. Shen, Y.-H. Luo et al., "Novel 1,4-naphthoquinone derivatives induce apoptosis via ROS-mediated p38/MAPK, Akt and STAT3 signaling in human hepatoma Hep3B cells," The International Journal of Biochemistry \& Cell Biology, vol. 96, pp. 9-19, 2018.

[22] J.-R. Wang, G.-N. Shen, Y.-H. Luo et al., "The compound 2(naphthalene-2-thio)-5,8-dimethoxy-1,4-naphthoquinone induces apoptosis via reactive oxygen species-regulated mitogen-activated protein kinase, protein kinase $B$, and signal transducer and activator of transcription 3 signaling in human gast," Drug Development Research, vol. 79, no. 6, pp. 295-306, 2018.

[23] Y. Wang, Y. H. Luo, X. J. Piao et al., "Novel 1,4-naphthoquinone derivatives induce reactive oxygen species-mediated apoptosis in liver cancer cells," Molecular Medicine Reports, vol. 19, no. 3, pp. 1654-1664, 2019.

[24] R. McCall, M. Miles, P. Lascuna et al., "Dual targeting of the cancer antioxidant network with 1,4-naphthoquinone fused gold(i) N-heterocyclic carbene complexes," Chemical Science, vol. 8, no. 9, pp. 5918-5929, 2017.

[25] Y. Zhang, Y.-H. Luo, X.-J. Piao et al., "The design of 1,4naphthoquinone derivatives and mechanisms underlying apoptosis induction through ROS-dependent MAPK/Akt/ STAT3 pathways in human lung cancer cells," Bioorganic \& Medicinal Chemistry, vol. 27, no. 8, pp. 1577-1587, 2019.

[26] M. H. Hodroj, A. Jardaly, S. Abi Raad, A. Zouein, and S. Rizk, "Andrographolide potentiates the antitumor effect of topotecan in acute myeloid leukemia cells through an intrinsic apoptotic pathway," Cancer Management and Research, vol. 10, pp. 1079-1088, 2018.

[27] D. Zhao, W. M. Tahaney, A. Mazumdar, M. I. Savage, and P. H. Brown, "Molecularly targeted therapies for p53-mutant cancers," Cellular and Molecular Life Sciences, vol. 74, no. 22, pp. 4171-4187, 2017.

[28] J. Liu and C. Zhang, "Tumor suppressor p53 and its gain-offunction mutants in cancer," Acta Biochimica et Biophysica Sinica, vol. 46, no. 3, pp. 170-179, 2014.

[29] Y. Feng, Y. H. Luo, S. M. Li et al., 2-(Naphthalene-2-Thio)-5, 8Dimethoxy-1,4-Naphthoquinone Induces Apoptosis Via RosMediated Mapk, Akt, And Stat3 Signaling Pathways In Hepg2 Human Hepatocellular Carcinoma Cells, pp. 1-11, Taylor \& Francis, Abington, UK, 2019.

[30] S.-G. Park, S.-H. Kim, K.-Y. Kim et al., "Toyocamycin induces apoptosis via the crosstalk between reactive oxygen species and $\mathrm{p} 38$ /ERK MAPKs signaling pathway in human prostate cancer PC-3 cells," Pharmacological Reports, vol. 69, no. 1, pp. 90-96, 2017.

[31] C. Zhang, Y. Yu, Q. Huang, and K. Tang, "SIRT6 regulates the proliferation and apoptosis of hepatocellular carcinoma via the ERK1/2 signaling pathway," Molecular Medicine Reports, vol. 20, no. 2, pp. 1575-1582, 2019.
[32] Y. Li, W. Sun, N. Han et al., "Curcumin inhibits proliferation, migration, invasion and promotes apoptosis of retinoblastoma cell lines through modulation of miR-99a and JAK/ STAT pathway," BMC Cancer, vol. 18, no. 1, p. 1230, 2018.

[33] D.-b. Liu, G.-y. Hu, G.-x. Long, H. Qiu, Q. Mei, and G.-q. Hu, "Celecoxib induces apoptosis and cell-cycle arrest in nasopharyngeal carcinoma cell lines via inhibition of STAT3 phosphorylation," Acta Pharmacologica Sinica, vol. 33, no. 5, pp. 682-690, 2012.

[34] J. M. Mast, D. Tse, K. Shee et al., "Diarylidenylpiperidones, $\mathrm{H}-4073$ and HO-3867, induce G2/M cell-cycle arrest, apoptosis and inhibit STAT3 phosphorylation in human pancreatic cancer cells," Cell Biochemistry and Biophysics, vol. 77, no. 2, pp. 109-119, 2019.

[35] M. Subramaniam, S. K. Liew, K. Awang, N. Ahmed, and N. H. Nagoor, "Inactivation of nuclear factor \& kappa;B by MIP-based drug combinations augments cell death of breast cancer cells," Drug Design, Development and Therapy, vol. 12, pp. 1053-1063, 2018.

[36] C. In, W. Zuo, X. Wang, L. Wei, Q. Guo, and X. Song, "Lapatinib inhibits the activation of NF- $\kappa$ B through reducing phosphorylation of IkB- $\alpha$ in breast cancer cells," Oncology Reports, vol. 29, no. 2, pp. 812-818, 2013.

[37] J. H. Park, Y. H. Seo, J. H. Jang et al., "Asiatic acid attenuates methamphetamine-induced neuroinflammation and neurotoxicity through blocking of NF-kB/STAT3/ERK and mitochondria-mediated apoptosis pathway," Journal of Neuroinflammation, vol. 14, no. 1, pp. 240-254, 2017.

[38] Y. Yang, G. Wang, W. Wu et al., "Camalexin induces apoptosis via the ROS-ER stress-mitochondrial apoptosis pathway in AML cells," Oxidative Medicine and Cellular Longevity, vol. 2018, Article ID 7426950, 14 pages, 2018.

[39] C.-Y. Lee, C.-H. Su, P.-K. Tsai et al., "Cadmium nitrate-induced neuronal apoptosis is protected by $\mathrm{N}$-acetyl-l-cysteine via reducing reactive oxygen species generation and mitochondria dysfunction," Biomedicine \& Pharmacotherapy, vol. 108, pp. 448-456, 2018. 